\title{
Element intoxication by marine food
}

\author{
Fatma Ates Alkan ${ }^{1}$, M. Ethem Koksal ${ }^{2}$, Dilek Duzgun Ergun ${ }^{1}$,Denizhan Karis ${ }^{1}$, \\ Nural Pastaci Ozsobaci ${ }^{1}$, Umit Bora Barutcu ${ }^{1}$
}

\begin{abstract}
Introduction: Pollution is deformation of natural condition of earth with physical, chemical and biological factors. Environmental pollution suppresses life balance and has negative effect on living and ecosystem with its effects on the food chain. Toxic metal pollution easily enters to food chain and accumulates in the living body. Marine species are intensely exposed to toxic metals, because of its habitats and feeding habits, and metals accumulate in their body.

Material and Methods: A 56 year-old obese male patient attended to Ortakent-Yahsi Family Health Center (Bodrum, Mugla, Turkey) with the symptoms of palpitation, constipation, long-term muscle contraction in January 2014. VEGA test resulted in toxic load accumulation. The pre-treatment and inter-treatment blood/serum levels of a group of trace/toxic elements were measured with Inductively Coupled Plasma Optical Emission Spectrometer (ICP - OES) at Istanbul University Cerrahpasa Medical Faculty, Biophysics Department. Neural therapy and chelation therapy were initiated to the patient by his doctor at Yahsi Family Health Center in February 2014.

Results: The pre-treatment values of blood/serum phosphor, selenium, nickel, arsenic and aluminium levels were analyzed higher than reference ranges. The inter-treatment blood/serum levels of selenium, nickel and aluminium decreased by November 2014, however blood/serum levels of phosphor and arsenic were still higher than reference values. The patient is still under medical supervision and treatment by his generalpractitioner

Conclusion: There is limited data related with the trace/toxic contamination of marine food in humans. The evaluation of trace and toxic elements might have significant value in diagnosis, treatment and follow-up of the individuals in contaminated environment and especially in seafood consumers.
\end{abstract}

Key words: Marine food, trace element, toxicity, VEGA test, chelation therapy.

\section{Introduction}

Environmental pollution deteriorates life balance and has negative effects on living organisms and ecosystems in Turkey, as well as in all over the world. Toxicity resulting from toxic elements and chronic toxicity of trace elements have been the highlight environmental problem in recent years in Turkey. Toxic element pollution originated from various sources infiltrates easily through food chain and accumulates in living organisms. Thus, toxicity of elements acts as the leading factor among other chemical pollutes. Urbanisation, tourism, coastal population, agriculture, maritime traffic and the influence of fisheries augment the risks of coastal and marine degradation in regions of semi-enclosed seas such as the Mediterranean Sea [1].

Marine food especially fish has high protein content and low saturated fatty acids such as omega fatty acids, thus it is an important food resource for human consumption in healthy diet being at the the top of the aquatic food chain $[2,3]$.
Elements can be divided into two groups; trace and toxic elements. Trace elements are dietary elements that are needed in very minute quantities for the proper growth, development, and physiology of the organism. Toxic elements can bioaccumulate in the body and in the food chain. Therefore, a common characteristic of toxic element is the chronic nature of their toxicity. Marine food is intensely exposed with toxic elements by means of their habitat and dietary habit and transmits the toxication to human beings. Although many elements found in marine food are essential for human life in low doses, these elements may have negatoroius effects even with low doses. Thus, elements in marine food may be hazardous for consumers and may be a good indicator for toxic metal contamination in aquatic systems [4]. Fish is gradually exposed to toxic elements and chemicals through water and food resulting in bioaccumulation in different fish organs $[5,6]$. 
The concentrations of toxic elements in fish alter in various species and different aquatic systems [7]. The toxic elements uptake from polluted water may vary according firstly to the grade of water, food and sediment accumulation; secondly to the ecological needs and metabolism of the system and thirdly to the biological and environmental factors such as size, age, feeding habit, temperature and dissolved oxygen [8, 9]. Toxic elements tend to accumulate in target organs like liver, gonads, kidney and gills in high concentration. Muscle is not an active tissue for bioaccumulation of toxic elements [10]. Gills are the first organ of the fish in contact with the sea water, thus they can readily reflect the concentrations of toxic elements in the ecosystem $[11,12]$. Due to the fact that of short distance between blood and sea water, toxic elements may directly pass through the gills [13]. Besides, gills can exchange toxic elements between the fish and the aquatic environment via its osmoregulation and gas exchange metabolism [11]. Moreover, crustacean seafood such as mullets, crabs and etc. can accumulate much higher levels of toxic elements than in the water [9].

Various ways of bioavailability of toxic elements include discrimination against the uptake of the toxic metal, incorporation of toxic elements within their bodies, distribution of toxic elements to tissues and organs and excretion via kidneys and digestive tract. Despite the excretion ability, chronical low-metal exposure may result in impaired functioning and chronic disease $[14,15]$.

Symptoms of energy imbalance in functional disturbances occur long before any pathological morphology is evident. The first sign of pathology in the body is an electrical charge. VEGA test which is a non-invasive method of electro-dermal screening measures these bioenergetic phenomena by recording the change in skin conductivity after application of a small voltage. VEGA test can be held to investigate the toxic load accumulated in living organism; intestinal flora status; digestive disturbances; food sensitivity and vitamin, mineral and hormonal imbalance [16, 17].

Chelation therapy is a medical procedure that involves the administration of chelating agents to remove toxic elements from the body. It should only be used in people who have a diagnosis of metal intoxication [18]. Neural therapy is a medical approach of diagnosing and treating local pains and disturbances of the autonomic nervous system of the body's electrophysiology [19].

The aim of our study is to evaluate the relationship between trace/toxic element levels in blood and serum specimens and clinical findings of a 56 year-old male patient suffering from palpitation, constipation, long-term muscle contraction within a diet enriched with marine food.
Material and Methods

A 56 year-old obese male patient was in follow-up of the general-practitioner at Ortakent Yahsi Family Health Center (Bodrum, Mugla, Turkey) with the diagnoses of hypothyroidism, diabetes mellitus, hyperlipidemia, peripheric venous insufficiency, chronic obstructive pulmonary disease, gasto-oesefageal reflux, chronic sinusitis, backache. He attended to the health center suffering from palpitation, constipation, long-term muscle contraction within a diet enriched with marine food in January 2014. His biochemical evaluation was analyzed between physiological ranges. VEGA test resulted in toxic load accumulation. The pre-treatment and intertreatment blood/serum levels of calcium, phosphor, chromium, iron, copper, magnesium, manganese, selenium, zinc, bor, silicium, nickel, arsenic, lead, cadmium, cobalt, aluminium were measured with Inductively Coupled Plasma Optical Emission Spectrometer (ICP-OES) to evaluate the treatment efficacy at Istanbul University Cerrahpasa Medical Faculty Biophysics Department. Neural therapy and chelation therapy were initiated to the patient by his doctor with the aim of regulation the toxic element excretion in February 2014. The patient is still under medical supervision and treatment by his general-practitioner.

\section{Results}

The pre-treatment values of blood/serum phosphor, selenium, nickel, arsenic and aluminium levels were analyzed higher than reference ranges. The inter-treatment blood/serum levels of selenium, nickel and aluminium decreased by November 2014, however blood/serum levels of phosphor and arsenic were still higher than reference values (Fig 1, Fig 2). Pre- and inter-treatment blood/serum values of manganese were lower than reference ranges (Fig 3). Inter-treatment blood/serum lead level was analyzed higher than pre-treatment level by November 2014 (Fig 4). Pre-treatment and intertreatment blood/serum values of calcium, chromium, iron, copper, magnesium, zinc, bor, silicium, cadmium and cobalt were analyzed between reference ranges (Fig 5) (Table1). 

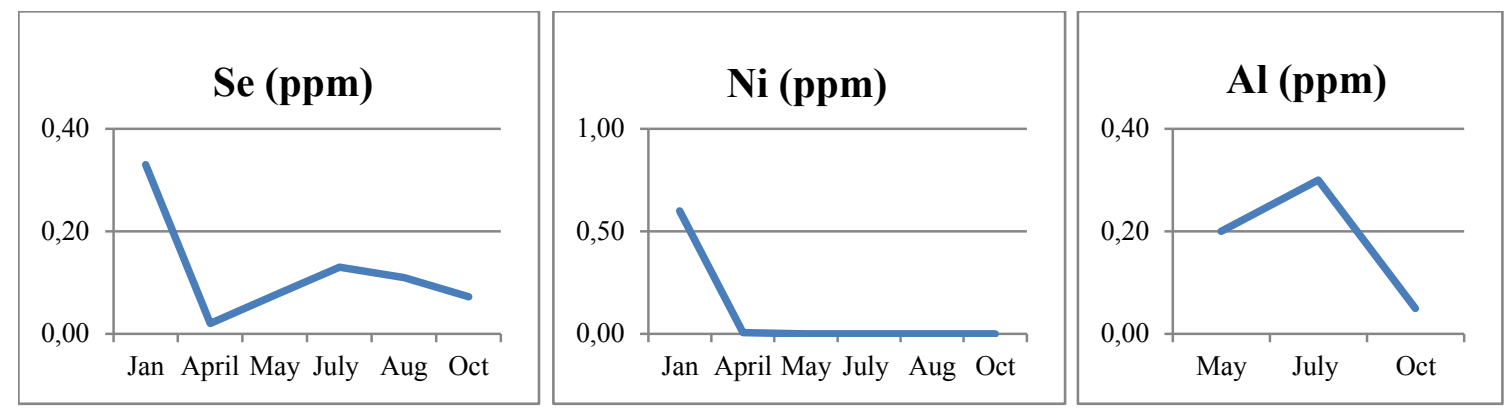

Figure 1: Blood/serum levels of pre-treatment elements levels higher than reference value, tending to decrease during inter-treatment.
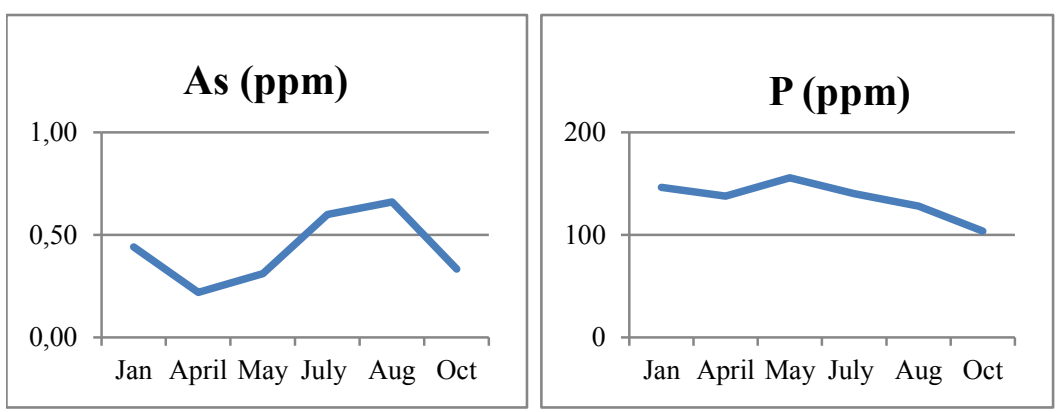

Figure 2: Blood/serum levels of pre-treatment and inter-treatment elements levels higher than reference values.

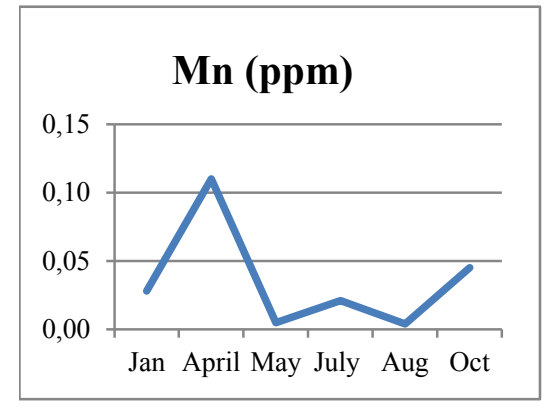

Figure 3: Blood/serum levels of pre-treatment and inter-treatment elements levels lower than reference values.

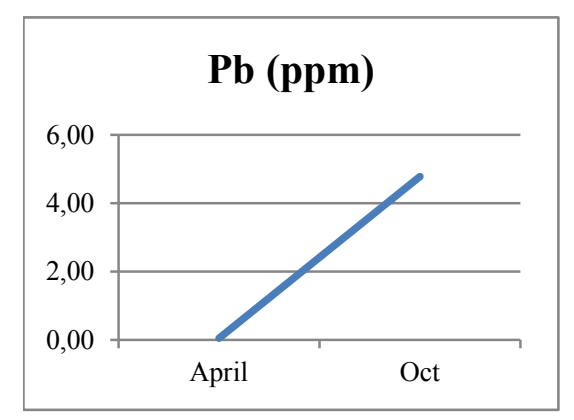

Figure 4: Blood/serum level of pre-treatment and inter-treatment element tending to increase. 

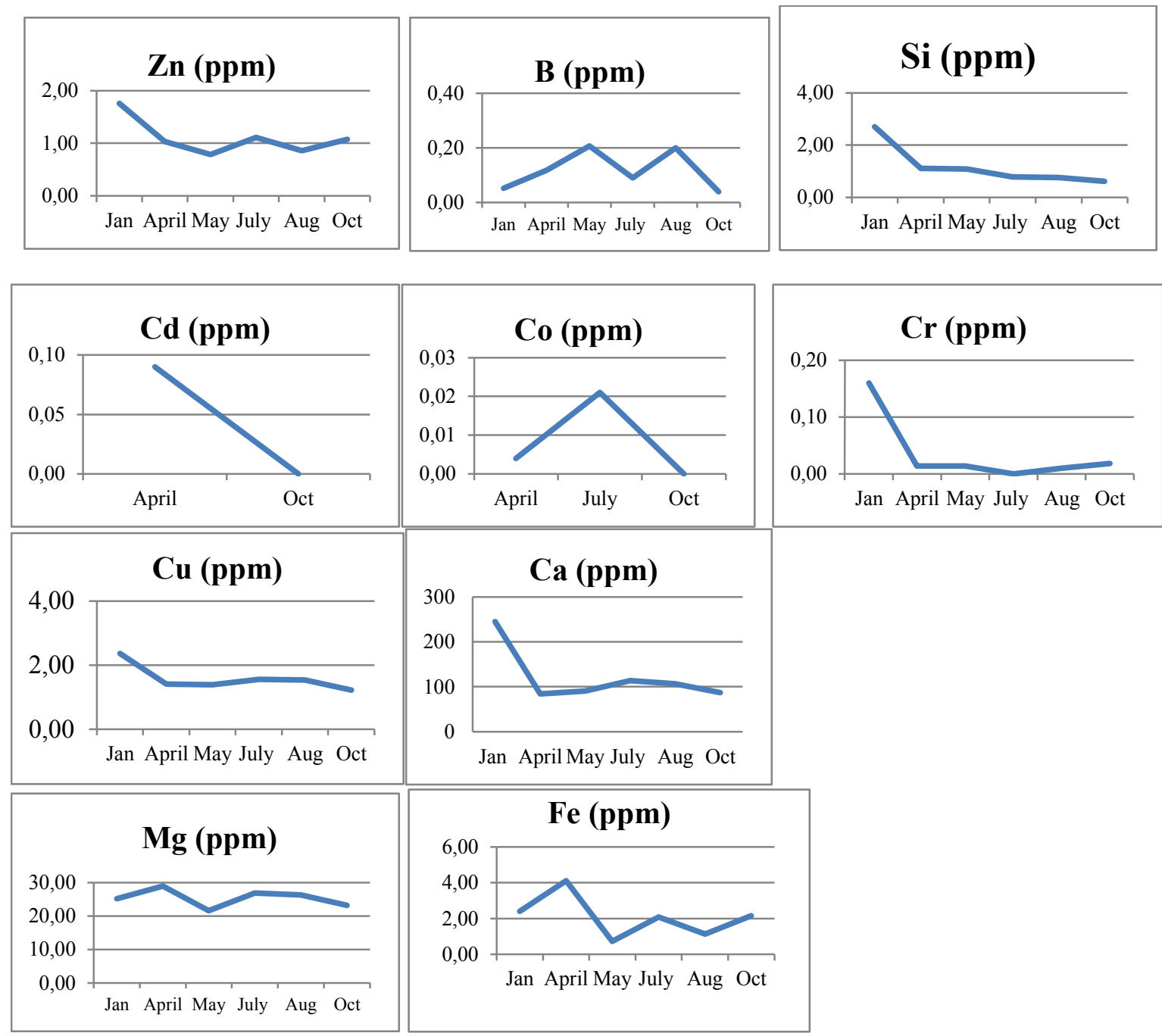

Figure 5: Blood/serum levels of pre-treatment and inter-treatment elements levels between reference values.

Table 1. Blood/serum values of the trace and toxic elements. ((-): Not measured.)

\begin{tabular}{cccccccc}
\hline Element & $\begin{array}{c}\text { January } \\
(\mathbf{p p m})\end{array}$ & $\begin{array}{c}\text { April } \\
(\mathbf{p p m})\end{array}$ & $\begin{array}{c}\text { May } \\
(\mathbf{p p m})\end{array}$ & $\begin{array}{c}\text { July } \\
(\mathbf{p p m})\end{array}$ & $\begin{array}{c}\text { August } \\
(\mathbf{p p m})\end{array}$ & $\begin{array}{c}\text { October } \\
(\mathbf{p p m})\end{array}$ & $\begin{array}{c}\text { Reference } \\
\text { Range } \\
(\mathbf{p p m})\end{array}$ \\
\hline $\mathbf{C a}$ & 245.2 & 84.1 & 90.8 & 114 & 107 & 87.3 & $85-115$ \\
$\mathbf{P}$ & 146.2 & 137.9 & 155.7 & 140.2 & 127.9 & 103.4 & $25-45$ \\
$\mathbf{C r}$ & 0.160 & 0.014 & 0.014 & 0 & 0.010 & 0.018 & $0.05-0.5$ \\
$\mathbf{F e}$ & 2.40 & 4.11 & 0.72 & 2.08 & 1.12 & 2.15 & $0.9-1.2$ \\
$\mathbf{C u}$ & 2.36 & 1.41 & 1.39 & 1.55 & 1.53 & 1.22 & $1.0-2.0$ \\
$\mathbf{M g}$ & 25.20 & 28.91 & 21.62 & 26.89 & 26.28 & 23.18 & $17-30$ \\
$\mathbf{M n}$ & 0.028 & 0.110 & 0.005 & 0.021 & 0.004 & 0.045 & $1.9-5.8$ \\
$\mathbf{S e}$ & 0.33 & 0.02 & 0.08 & 0.13 & 0.11 & 0.07 & $0.0005-0.0015$ \\
$\mathbf{Z n}$ & 1.76 & 1.03 & 0.79 & 1.11 & 0.86 & 1.07 & $0.7-1.2$ \\
$\mathbf{B}$ & 0.052 & 0.118 & 0.207 & 0.090 & 0.200 & 0.039 & $0.033-0.191$ \\
$\mathbf{S i}$ & 2.70 & 1.11 & 1.08 & 0.78 & 0.76 & 0.61 & $0.4-10$ \\
$\mathbf{N i}$ & 0.600 & 0.006 & 0 & 0 & 0 & 0 & $0.00005-0.0011$ \\
$\mathbf{A s}$ & 0.44 & 0.22 & 0.31 & 0.60 & 0.66 & 0.33 & $0.001-0.004$ \\
$\mathbf{P b}$ & $(-)$ & 0.055 & $(-)$ & $(-)$ & $(-)$ & 4.780 & $0-0.04$ \\
$\mathbf{C d}$ & $(-)$ & 0.09 & $(-)$ & $(-)$ & $(-)$ & 0 & $0-0.01$ \\
$\mathbf{C o}$ & $(-)$ & 0.004 & $(-)$ & $(-)$ & 0.021 & 0 & $0-900$ \\
$\mathbf{A l}$ & $(-)$ & $(-)$ & 0.20 & $(-)$ & 0.30 & 0.05 & $0.001-0.002$ \\
\hline & & & & & & &
\end{tabular}


Discussion

The excess consumption of marine food in which toxic elements highly accumulate is estimated to cause varied metabolic disorders. Trace/toxic elements can be hazardous for organisms even with low doses. Our patient had consumed excess amount of marine food including various fish, crustacean seafood such as mullets crabs and etc. resulting in various symptoms. The analysis of pre- and inter-treatment serum values of trace/toxic elements revealed different results including rises, reductions or steadiness. Neural therapy and chelation therapy were initiated to the patient. Trace/toxic elements are excreted from the body via urine, faeces, sweating, and exhalation in chelation therapy. The blood/serum fluctuations within reference ranges and increase of trace / toxic elements in chelation therapy might be due to the fact that elements are mobilized from tissues to blood circulation [20, 21].

In addition to chelation and neural therapy, the patient was advised to have a diet excluding refined wheat products and refined sugar and including well-balanced consumption of food with the possibility of sensitivity. Physical exercise was suggested accompanied with water consumption. The complaints and signs of our patient have ameliorated with ongoing treatment.

In conclusion, correlation between the complaints of the patient treated with chelation therapy and neural therapy and the decrease in the serum trace element levels revealed that treatment might ameliorate toxic element accumulation.

The contamination of the biological environment is a crucial issue related with the health of both aquatic animals and seafood consumers. Despite the inevitable industrialization, the main target of all human beings has to be the preservation of fresh and sanitated food for good health. The assessment of trace and toxic elements might have significant value in diagnosis, treatment and follow-up of the individuals in contaminated environment and especially in seafood consumers.

Acknowledgments: The authors do not have any financial interest in the companies whose materials are included in this article

Conflict of Interest: The authors declare no potential conflicts of interest with respect to the research, authorship, and/or publication of this article.

\section{References}

1. Yarsan E, Yipel M, Dikmen B, Altintas L, Ekici H, Koksal A. Concentrations of essential and non-essential toxic trace elements in wild boar (Sus Scrofa L., 1758) tissues from southern Turkey. Bulletin of environmental contamination and toxicology. 2014;92(1):10-4.

2. Ikem A, Egiebor NO. Assessment of trace elements in canned fishes (mackerel, tuna, salmon, sar- dines and herrings) marketed in Georgia and Alabama (United States of America). J Food Compos Anal. 2005;18:771787

3. Mansour SA, Sidky MN. Ecotoxicological studies. 3. Heavy metals contaminating water and fish from Fayoum Governorate, Egypt. Food Chem. 2002;78:1522.

4. Bat L, Sezgin M, Ustun F, Sahin F. Heavy metal consumers in ten species of fishes caught in Sinop Coastal waters of Black Sea, Turkey. TrJFAS. 2012;12:371-76

5. Burger J, Gaines KF, Boring CS, Stephens WL, Snodgrass J, Dixon C, et al. Metal levels in fish from the Savannah River: potential hazards to fish and other receptors. Environmental research. 2002;89(1):85-97.

6. Hadson PV. The effect of metabolism on uptake, diposition and toxicity in fish. Aquat Toxicol. 1988;11:3-18

7. Canli M, Atli G. The relationships between heavy metal $(\mathrm{Cd}, \mathrm{Cr}, \mathrm{Cu}, \mathrm{Fe}, \mathrm{Pb}, \mathrm{Zn})$ levels and the size of six Mediterranean fish species. Environmental pollution. 2003;121(1):129-36

8. Romeo M, Siau Y, Sidoumou Z, Gnassia-Barelli M. Heavy metal distribution in different fish species from the Mauritania coast. The Science of the total environment. 1999;232(3):169-75.

9. Beltrame MO, De Marco SG, Marcovecchio JE. Influences of sex, habitat, and seasonality on heavymetal concentrations in the burrowing crab (Neohelice granulata) from a coastal lagoon in Argentina. Archives of environmental contamination and toxicology. 2010;58(3):746-56

10. Yilmaz AB. Comparison of heavy metal levels of grey mullet (Mugil cephalus L.) and sea bream (Sparus aurata L.) caught in Iskenderun Bay (Turkey). Turk J Vet Ani Sci. 2005;29:257-62.

11. Hosseini M, Nabavi SBM, Pazooki J, Parsa Y. The levels of toxic metals in Blue Crab Portunus segnis from Persian Gulf. J Marine Sci Res Dev. 2014 ;4:145.

12. Kayhan FE. Bioaccumalation and toxicity of cadmium in the water products. EgeJFAS. 2006; 23(1-2):215-20.

13. M Stancheva, L Makedonski, E Petrova. Determination of heavy metals $(\mathrm{Pb}, \mathrm{Cd}$, As and $\mathrm{Hg})$ in Black Sea Grey Mullet (Mugil Cephalus). Bulg J Agric Sci. 2013;19(1):30-34.

14. Carnahan EA. Foraminiferal assemblages as bioindicators of potentially toxic elements in Biscayne Bay Florida. MSc Thesis. University of South Florida. Grandute School. 2005. 
15. Aygun SF, Abanoz FG. Determination of heavy metal in anchovy (Engraulis encrasicolus L 1758) and whiting (Merlangius merlangus euxinus Nordman, 1840) fish in the Middle Black Sea. Kafkas Uni Vet Fac Derg. 2011;17:145-152.

16. Lewith GT, Kenyon JN, Broomfield J, Prescott P, Goddard J, Holgate ST. Is electrodermal testing as effective as skin prick tests for diagnosing allergies? A double blind, randomised block design study. Bmj. 2001;322(7279):131-4.

17. Kiop J, Swierczek J, Wood A. Comparison of ecological testing with the Vega test method in identifying sensitivities to chemicals, foods and inhalants. Am J Acupuncture.1985;13:253-59.
18. Kosnett MJ. Chelation for heavy metals (arsenic, lead, and mercury): protective or perilous? Clinical pharmacology and therapeutics. 2010;88(3):412-5.

19. Ernst E, ed. Neural Therapy. Complementary Therapies for Pain Management: An Evidence-based Approach (Elsevier). 2007; p.149. ISBN 0-7234-3400$\mathrm{X}$.

20. Flora SJ, Pachauri V. Chelation in metal intoxication. International journal of environmental research and public health. 2010;7(7):2745-88.

21. Yang C, Marit AS, Ole A, Jan A. Chelation therapy in intoxications with mercury

Copyright (C) 2014 The Author(s); This is an open-access article distributed under the terms of the Creative Commons Attribution License (http://creativecommons.org/licenses/by/4.0), which permits unrestricted use, distribution, and reproduction in any medium, provided the original work is properly cited. 